\title{
Progress and Pitfalls in Community Mapping: Behaviors, Cognitions, and New Directions
}

\author{
Samuel Hammer ${ }^{1, \mathrm{a}}$ and Aidan Ackerman ${ }^{2, \mathrm{~b}}$ \\ ${ }^{1}$ College of General Studies, Boston University, 871 Commonwealth Avenue, Boston, MA \\ 02215, USA \\ ${ }^{2}$ Boston Architectural College, 320 Newbury Street, Boston, MA 02115, USA \\ acladonia@bu.edu, ${ }^{\mathrm{b}}$ Aidan.Ackerman@the-bac.edu
}

\begin{abstract}
This paper discusses three student projects in urban mapmaking. The product of all the projects was student-generated urban maps which documented specific aspects of the city of Boston, including architectural elements, ecological conditions, and patterns of human movement and behavior. Cloud-based digital technology including GPS and manual geo-location of information and the use of social media as a tool to collect and share information were core components of these projects. The paper presents methodologies, results, and reflections on the student learning process and engagement that occurred through the creation of these maps, theorizing about how students could build on these processes to support the creative process.
\end{abstract}

Keywords: Community mapping, social media, critical making, digital presence, urban observation.

\footnotetext{
"The only source of knowledge is experience." Einstein

"... the process of experience is more important than any special result attained, so that special results achieved are of ultimate value only as they are used to enrich and order the ongoing process."

John Dewey
}

\section{Introduction}

Community-built maps are a form of critical making, a hands-on activity that links digital technology to society. As in any hands-on activity, the key to learning is experience (see quotes above). In the mapmaking exercises described here, experience is seen as the source of knowledge, and this experience is harnessed in order to provide a cogent explanation of the real world.

Producing a digital map entails using material forms of engagement in order to extend critical reflection (Ratto \& Ree, 2012; Somerson \& Hermano, 2013), in which ideas populate a digital space that can be disseminated and communicated. Map-making can be seen as a way of constructing information (Bannon \& Bødker, 2012), through which hierarchies, concepts, and a shared information space emerge. Mapping is also a process, an exercise that enables students to uncover unseen realities (Corner, 1999). 
International Journal on Urban Environments

In a group mapping project, subjective itineraries (O'Rourke, 2013) are confronted by others' realities, a venture out of one's comfort zone into collaborative learning.

Civilian, scientific, and military use of GPS as a method of observation and critique of the built environment have progressed significantly over the past decade, transforming our understanding and experience of the places we inhabit and investigate. Not only is the physical surface of the Earth being mapped-human existence is undergoing a transformation as a result of this collectively presented information. Anything that is listed, counted, and linked to a physical or digital address can be mapped, and the persistent and age-old question of "Where am I?" can now be answered more definitively than has ever been possible (Kurgan, 2013).

Urban mapping might simply aim to make legible the complex, layered, often intangible elements that comprise modern urbanity. The map may in fact be the singular way in which the disparate elements within a city can achieve visual coherence. It may be enough simply to create a map, recognizing the distinct celebratory nature of rendering legible the complexities of contemporary urban systems and processes (Ntmann \& Hambourg, 2004). Another goal of urban mapping could be said to allow humans to gain closer access to urban themes through technology, providing opportunities for data mining which makes it possible for us to adapt to the environment (Contin et al., 2014). Collaborative maps also have the advantage of flexibly supporting a wider range of topics and themes compared to traditional maps, supporting emerging voices and narratives which would otherwise be on the fringe of the urban planning dialogue. These maps might incite participatory political discourse based on a shared agenda reflected in the maps, fostering awareness, agency, and civic participation which can catalyze positive spatial transformation (Contin et al., 2014)

The participatory process of gathering data and contributing it to a larger aggregate pool of information, otherwise known as "crowdsourcing," is considered to be one of the most significant innovations that has come about as a result of the use of social media. Through decentralizing the conception and execution of problem solving, multiple individuals are able to contribute to a larger pool of information and assets. This produces a versatile platform for learning, experimentation, innovation, and adaptation (Benkler, 2009). This platform allows innovators connect rapidly and efficiently across space and time, and supports individual and group contributions which otherwise would not have been possible due to the constraints of traditional project workflows (Fok, 2015). This also points towards a shift in who is qualified to create urban maps; where mapping used to be the domain of trained experts, advances in technology now allow people to create and share spatial information without great cost, expertise, or advance planning (Contin et al., 2014). Further challenging the notion of space and time as overlapping and connected, crowdsourced maps show uses, preferences, ideas, and images which lead the viewer to focus beyond the physical realities of the urban realm. Rather, the potential of digital technology and urban networks suggest the notion that cities and communities may no longer rely entirely on a collective relationship with time and place (Contin et al., 2014). 
International Journal on Urban Environments

This paper is in part a venture out of the authors' comfort zones. One author, a scientist, introduced mapping projects to highlight urban ecological questions. The other author, a landscape architect, taught mapping as a design process. But our common underlying goals-encouraging students' critical reflection, enhancing student observation, and building habits of lifelong learning, encouraged us to write this paper together. In this paper we discuss three projects through which undergraduate students engaged for the first time in urban map-building. Two of the projects (at Boston University) were performed by non-design students in the context of an urban ecology course. One of the projects (at the Boston Architectural College) was undertaken by first-year design students in the context of an introduction to the city. While the product of all three exercises was the development of studentgenerated maps, we discovered that the more critical outcome for us was the process by which students engaged with the projects, rather than the completed maps. According to Bloom's taxonomy (1956) the process of "application" (making the maps) is a lower affective domain than the analysis, synthesis, and evaluation that goes into making them. Following this line of reasoning, "creation" is the highest domain, leading us to theorize about how students might build upon the process of applying data and evaluating their maps, and whether this process can support a creative end product — such as an environmental strategy or a site design.

We attempt here to assess students' critical reflection during the projects, a qualitative undertaking that we consider as valuable as any quantitative outcome. We also review our design goals for these projects in light of the activities and behaviors demonstrated by our students. Finally, we identify future directions for deeper engagement with critical making, in an attempt to utilize the great potential of community mapping.

\section{Goals for the Projects}

Our major goal for students was critical reflection and deeper engagement with critical making. In order to accomplish this, a first step was to introduce a framework that felt relevant to students. We designed projects in which students could experience a relatively high degree of autonomy in a low-stress classroom setting. We wanted to create an unobtrusive learning environment where students could contextualize, connect and synthesize their findings. In order to accomplish these objectives, two of the three projects were field-based (a record-breaking snowfall that paralyzed Boston for a month forced the third project indoors). By situating themselves in the city, students built a connection that they could later translate into the map. Physically engaged in the city, students had the opportunity to observe closely, to spend time reflecting, and to literally touch the city. We believe that physical engagement with the city also encouraged buy-in from students. We hoped that mapping might help organize the mass of details and impressions experienced in the city. We chose digital formats for several reasons. First and foremost, we believe that the online environment promotes a sense of audience for any project (Marwick \& Boyd, 2010). Whether we use google maps, flickr, twitter, or other social media, the potential for sharing and feedback, either in the classroom or at a global scale, is realizable (Das, 2011). Second, digitally-based work, whether it involves photographic capture, image 
International Journal on Urban Environments

analysis, or manipulation allows students to engage with a large body of data in a reasonable package. Finally, students' "natural habitat" is with their electronic devices. This may be the most comfortable niche for learning activities (Hammer, 2014). Older undergraduate and graduate students who were not "digital natives" similarly connected with the technology and found it familiar and comfortable. Mostly our goals were based more on cognitive development and behaviors vs. "skills." In relative order, these goals were:
1. Connecting/contextualizing
2. Critical analysis
3. Engagement
4. Simple workflow
5. Transfer of observation onto map format

\section{Methodologies}

These projects were carried out using methods of participant observation and reflection; the methods by which students carried out the project are discussed herein. The authors of this paper were involved in the projects and closely observed the progress and learning outcomes of the students. In all of the projects, students were expected to connect their map work with course concepts, with real-life examples, and with their own cognitive map. For one project, students connected their mapping work (Fig. 1) to the urban heat island effect (UHI) by associating low vegetative cover with UHI.

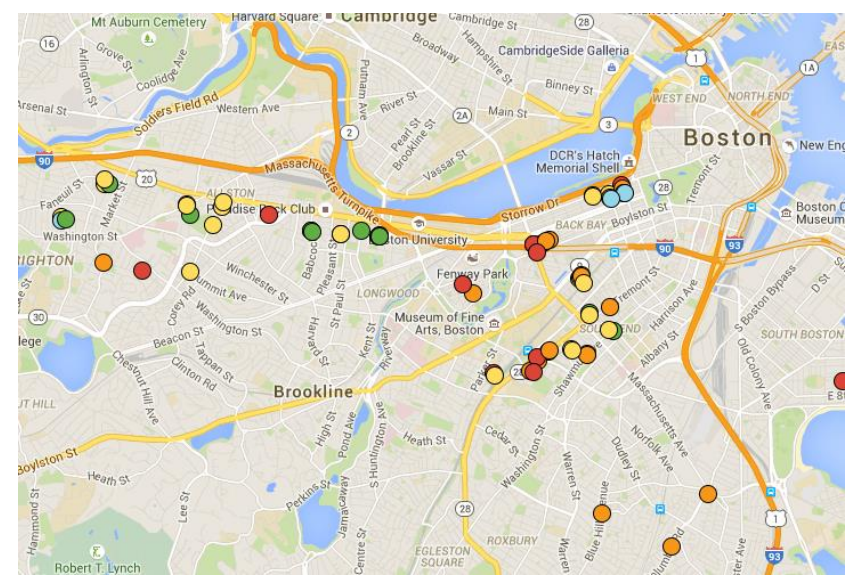

Fig. 1: Student generated map of the urban heat island effect in Boston.

Red, yellow, orange $=$ transects with low vegetative cover.

Green, blue $=$ transects with relatively high vegetative cover.

Source: google maps (https://www.google.com)

In the second project (Fig. 2) students mapped soil types in several Boston neighborhoods. Both of these projects supported the urban ecology curriculum. They connected to real life via student forays into well-known neighborhoods close to the Boston University campus. 


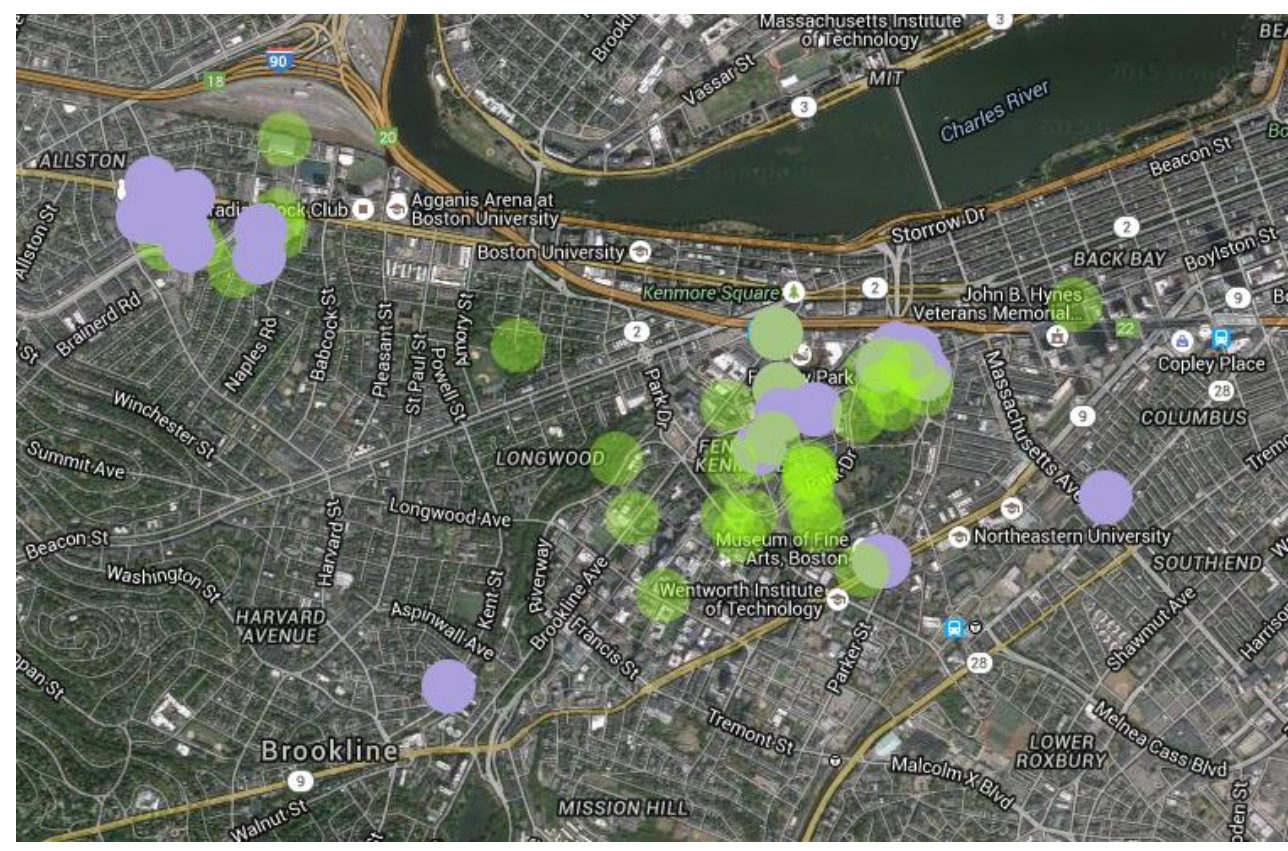

Fig. 2: Student generated map of soil characteristics in Boston. Green dots = predominantly organic soils.

Purple dots = predominantly inorganic soils.

Source: google maps (https://www.google.com) with interventions by the authors

The third project (Fig. 3) involved students documenting and analyzing sites in various neighborhoods in Boston, in order to characterize distinct urban zones. Here the design curriculum was supported and cognitive maps were featured (and perhaps challenged). In two of the exercises, (soil types and neighborhoods) students collected data on-site. In the UHI mapping exercise, students studied prepared urban transects and inferred UHI from the vegetative cover they estimated. For the soil analysis map, students collected samples themselves, took notes on the immediate environment, and pinpointed where in the city they collected. For the city neighborhood map, students photographed and commented on features of various neighborhoods, finally aggregating their photos to detect patterns of neighborhood character. 
International Journal on Urban Environments

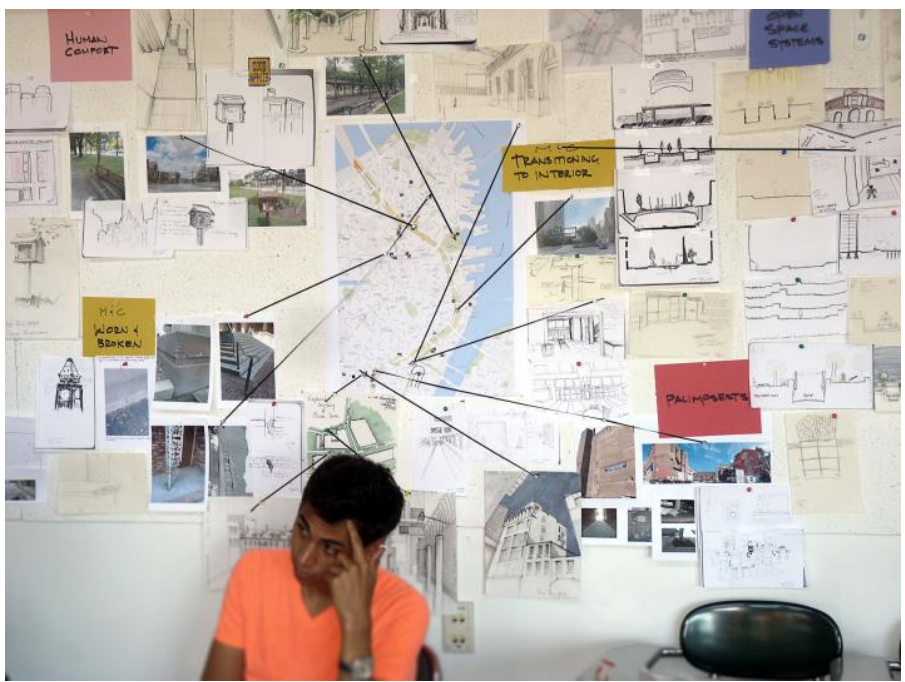

Fig. 3: Student generated map of visual cues in Boston Source: Ackerman and Garver, 2015

In all three exercises, students were required to manipulate digital images. The simplest exercise for students was the UHI mapping exercise, where students visually observed vegetative cover vs. built surfaces and inferred the UHI based on these observations (Fig. 4).

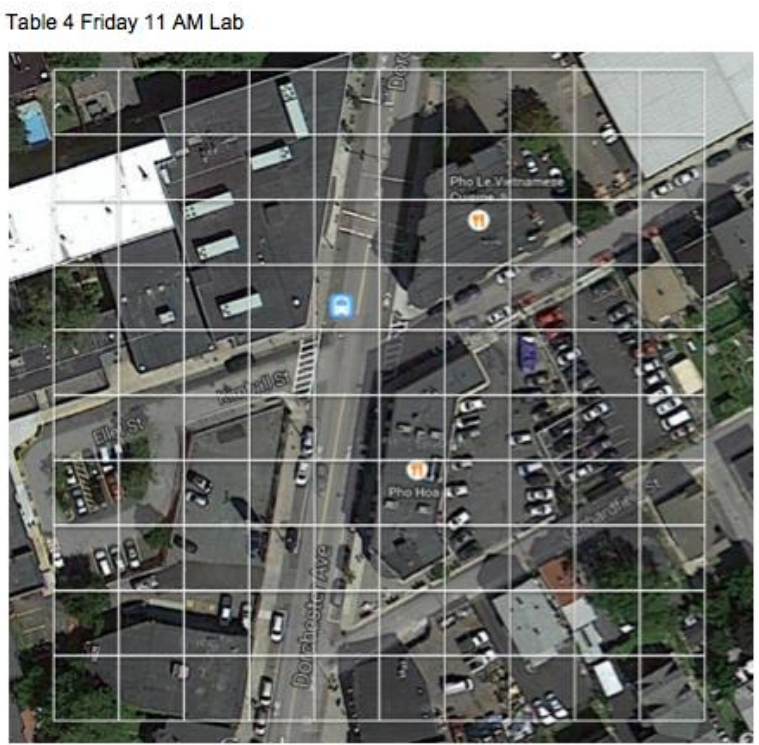

Location: Dorchester Avenue and Kimball Street, Boston

Fig. 4: Urban transect for estimating plant cover.

Source: google maps (https://www.google.com) with interventions by the authors

The soil analysis map was more complicated for students. After the samples were collected, students observed several google images of soil and compared the digital images with microscopic samples they prepared. Through subjective evaluation, they decided whether their sample was predominantly organic or inorganic. In both the 
International Journal on Urban Environments

UHI and soil analysis mapping exercises students found the actual placing of points on the map to be the most challenging activity because it involved several steps beyond the initial evaluation of data (Fig. 5). Over 70 of these transects were preprepared (ca. 1 per student) to permit easy analysis during the lab period. The professor also provided the exact location of each map so students could conveniently google the location and drop a point there. Each transect required ca. 10 steps by the professor. The goal was to keep the workflow simple for these non-science undergraduates, in order to encourage engagement with the ecology concepts of the lab.

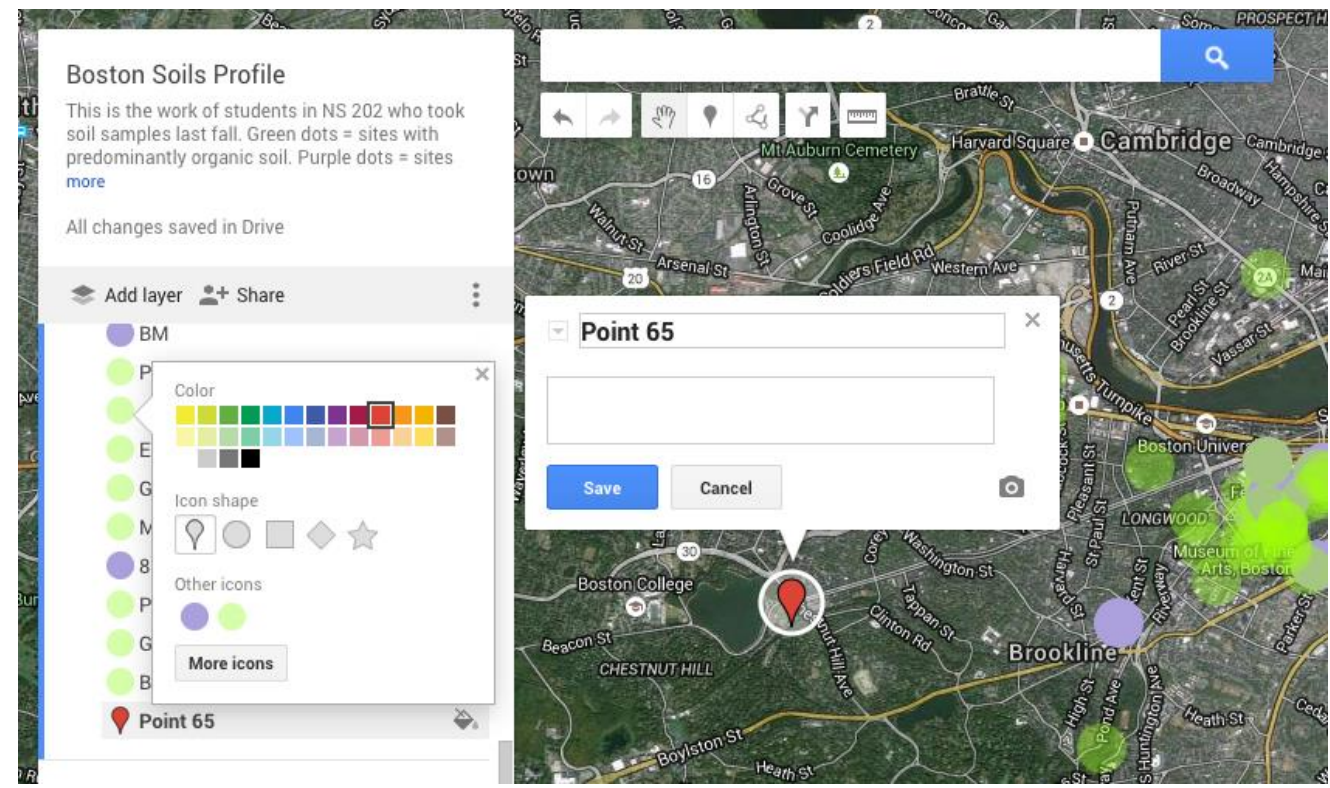

Fig. 5: Mechanics of the Mapping Process Using Google Maps Source: google maps (https://www.google.com) with interventions by the authors

This simple mapping process required three steps. a) Student places marker on map ("point 65"); b) Student clicks on "paintbucket" (not visible, lefthand box) that reveals "color" box (lefthand side); c) Student chooses and clicks appropriate "other" icon from bottom of the pop-up color box. Approximately $40 \%$ of students could not complete this process without help.

The neighborhood mapping project involved the most complex digital manipulations. In addition to taking photos, students were required to select, download, catalogue, trim, aggregate, and arrange images in a series of steps. These steps required ca. 20 discrete instructions and 18 instructional illustrations (Fig. 6). The result was a map to be used as an organizing space. Students printed the map in large format and wallmounted it as a space to attach other printed photos, write comments, and generate conversation (see Fig. 3). 
International Journal on Urban Environments
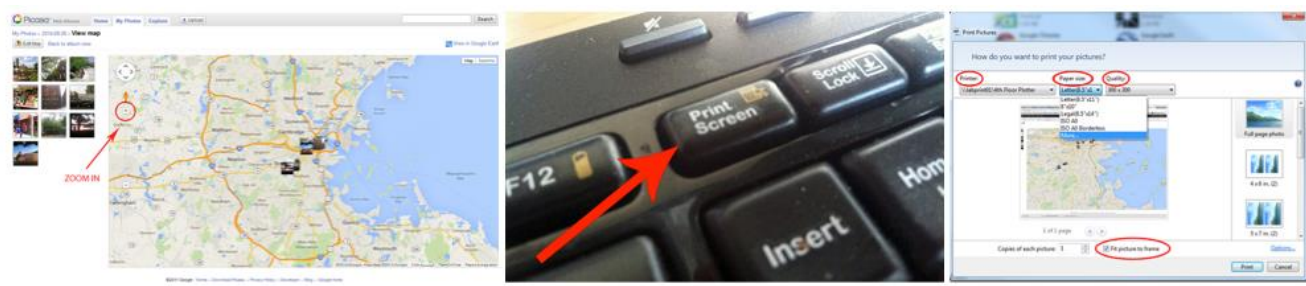

Fig. 6: Examples of instruction pages for city neighborhoods mapping project.

Source: google maps (https://www.google.com) with interventions by the authors

These methods utilize participatory experience as the primary means of achieving high levels of student engagement with the subject material. Compared with disconnected methods of absorbing course content such as lectures, readings, and research done by gazing at a screen, the authors' methodologies prioritize field experience over rote learning. The tangible results that are the outcomes of these methodologies are therefore of high value and interest to the students. Methods of participatory observation, capture, collection, and synthesis of information in turn yield greater student connection with findings. These efforts foster a learning environment which values critical analysis and reflection, both with regard to the processes that were undertaken, and the meaning and value of the work that was done.

Some limitations with this methodology became evident towards the end of all three projects. Critical analysis on the part of the students could have been stronger. In all cases, the participatory process of observation and notation was not effectively situated as a moment for deeper inspection, evaluation, and reflection about the information being documented. Rather, these moments became steps towards an end goal of creating a map of information. This is discussed in more specific detail below.

\section{Findings \& Analysis}

The three map projects studied here range from a more or less strictly quantitative project (UHI) to one involving a mix of quantitative/qualitative judgments (soil analysis), to a project in which predominantly qualitative decisions drove the finished product (city neighborhoods). In the same sequence, the projects ranged from greater top-down instruction (less student autonomy) to less top-down instruction (more student autonomy) (Fig. 7). This issue is important in terms of the question, "how much are we driving the outcome of the maps?" The effort (by professors) expended in preparation seems to be fairly similar for all three projects, approximately 70 hours for the beta run of each of these mapping experiments. 
International Journal on Urban Environments

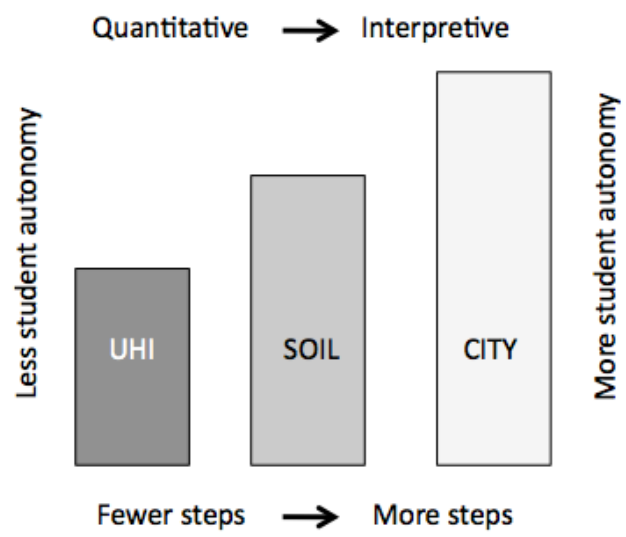

Fig. 7: Student Autonomy as Part of the Process Source: Author

Considering our goals for all three projects, we found that our design goals were met with a medium to high level of our expectations (Fig. 8). Students connected with all of the projects at a high level. For example, students communicated about the soil analysis lab in these representative statements:

\footnotetext{
"I really enjoyed this lab it was great to learn about the area we walk through everyday."

“...plotting where the soil sample was located was interesting. I want to see this map after everyone plots their soil spots!"

"This lab worked well! I learned how to identify soil. And how to plot the location of the soil on a map."

"Really enjoyed this lab, it's been so long since I've used microscopes! Very cool to collect soil in my own backyard as well!"

"I thought this lab was very helpful with understanding the role of soil in our urban lifestyle."
}

$\begin{array}{llll} & \text { UHI } & \text { SOIL } & \text { CITY } \\ \text { Connecting/contextualizing } & \text { high } & \text { high } & \text { high } \\ \text { Critical analysis } & \text { med } & \text { med } & \text { med } \\ \text { Engagement } & \text { med } & \text { high } & \text { high } \\ \text { Simple workflow } & \text { high } & \text { med } & \text { low } \\ \text { Transfer onto map format } & \text { med } & \text { med } & \text { med }\end{array}$

Fig. 8: Comparing goals and outcomes of three mapping projects Source: Author

Contextualizing was high in all projects while critical analysis was poorly measured. The workflow was the most variable outcome.

The comments above are helpful in assessing student engagement. We see the benefit of solitciting student responses during and immediately after the activity, and we will introduce that in future projects. 
International Journal on Urban Environments

We feel that we did not assess critical analysis of the work adequately. From a subjective standpoint it would seem that critical analysis was satisfactory, but could have been higher in all of the projects. In the UHI, students performed a simple estimation of plant cover (negatively associated with the urban heat island effect) and plotted their estimates on a map. Part of the warm-up for the mapping project included readings on the urban heat island effect, as well as texting parents during class to discover how much each family spent on cooling their house. However, as is often the case, the "end product," (plotting the point) became the focus of the lab instead of a means toward further interpretation. Ironically, we found that the same situation applied to the most complex, student-centered mapping project, in which students spent many hours in the city observing, documenting, and thinking about neighborhood characteristics. The field activity played a significant role in connecting and contextualizing but ultimately students struggled with the complicated steps of preparing the map. Again, the map itself became the "end," rather than a means for interpretation. As we evaluated the students' finished products from the neighborhood mapping project, perhaps the best indication of students' critical thinking emerged not from the maps themselves, but from the social media products of their observations. While the end point of creating maps served more as a collection and organization tool, the act of collecting supported higher-level thinking. We observed that social media enabled many students to synthesize their reactions to what they had captured and mapped, as well as site-specific information such as materiality, transition, and age (Fig. 9). Students seem to have performed the highest level of critical thinking in the soil analysis mapping project. The several steps involved in the project were simple to fulfill but required hands-on involvement in a range of activities: reading a paper map to find the assigned neighborhood for collecting, gathering a soil sample, pinpointing a location manually (not using a digital locator), reading a short essay on soil types, preparing a microscope sample, comparing the sample with published photos online, and making a judgement about soil quality.

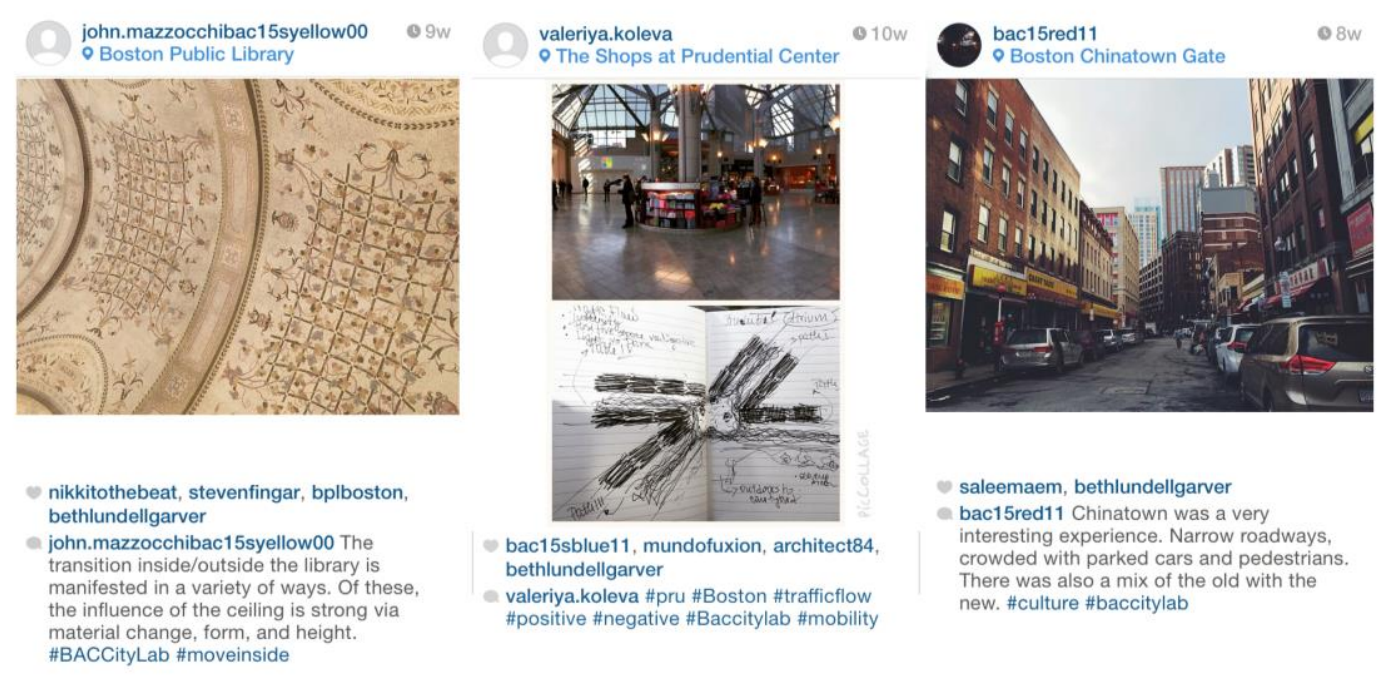

Fig. 9: Student generated Instagram posts

All posts were georeferenced, tagged with \#BACCityLab, and were later placed on a map

Source: Ackerman and Garver, 2015 
International Journal on Urban Environments

\section{Discussion}

We learned at least as much as our students during these mapping exercises. First, the value of immediate student feedback is very high, and should be solicited in future projects. Asking a series of questions allows students to explore their own learning further. Where opinions, rather than "positive" responses are elicted, students can provide us with a goldmine of information into how they think and learn. The process of feedback can be informal and almost instantaneous, for example by using twitter. Fascinating questions have emerged from this student-produced wealth of information, namely how to locate and aggregate written and visual material to understand what general observations and viewpoints are most common across a student group. Drawing from a wealth of existing methodology in the area of qualitative social research originating in disciplines such as social anthropology and sociology, perhaps written and photographed student work could be sorted by keyword, phrasing, type of image, and even visual construction of the image. This in turn might provide valuable information about the shared observations and evaluations of the student group as a whole (Knoblauch et al., 2008). Second, consideration must be given to simplifying, but perhaps not over-simplifying the workflow. Student buy-in and engagement are associated with a meaningful hands-on process that requires some physical work, similar to the soil sample lab. But too many steps submerge the project into technological minutae that might not lead to a desireable outcomes. How can we balance the complex process of data gathering with the demands of critical analysis? Finally, we need to focus on particular measures that will assess students critical thinking. In addition to asking about engagement, we may ask students how a particular activity encouraged them to use critical analysis. Like other evaluative feedback, this can be accomplished informally and quickly by using twitter and encouraging students to develop their own vocabulary of critical thinking. From another perspective, we need to ask ourselves which expectations are reasonable in terms of student critical analysis. What can we expect from students who are new to the process of digital mapping? How can we ask them to step back, think critically, and reflect on the process of discovery that leads to making a map? How can we accomplish group map-making without making the map becoming the primary focus? In exploring Kurgan's age-old prompt of "Where am I?", this process challenges students to take a step towards finding their own answer to this question. This answer becomes clearer to students through their revelation that they exist within a community that is fluid, complex, layered, and defies simple definition. Through making tangible the elements that surround them, perhaps the first steps are taken towards a healthy dialogue about the role of the individual within a larger community. That these elements are crowdsourced serves to further bolster the discussion; a diversity of results makes evident the shared and differentiated values among the group. Such findings further the discussion on what defines a modern community, and the agency of the individual to enact positive social and environmental change as part of these communities. 
International Journal on Urban Environments

\section{Conclusions and New Directions}

Overall, the projects were largely successful and student learning outcomes were high. By enacting frameworks that were autonomous and low-stress, students were able to engage with the processes of contextualizing, connection, and synthesizing their findings. The prioritization of simple workflows allowed a high number of students to successfully complete the work, creating the desired end product of a digitized map of information. For the future, the authors recommend that there be greater support for critical analysis of the work that was undertaken by the students. As noted earlier, many students did not effectively move beyond the map-making exercise itself to reflect on the role of the work they had undertaken. Nor did many students experience larger-scale realizations about the complexities, contradictions, and emerging potential discovered within the communities they studied. Greater support for these important discussions and reflections is necessary and essential throughout the project.

We identified three areas that we would like to pursue further. First, while we have attempted to provide an innovative learning environment we have perhaps overlooked the importance of student innovation. Whichever career path they choose, students will have to innovate in the workplace. Increasing complexity and inter-relatedness of problems will require critical thinking that goes beyond any one discipline we can teach (Hammer, 2015). How can we bring more innovation to student endeavors? Second, how can we encourage students to build maps that truly uncover new, unseen information? Uncovering new information may be tied to close observation, a second goal of our future work with student mapping. Close observation enables students to ask unexpected questions, relying on their own cognitive pathways to define inquiry. Our goal of producing lifelong learners requires that we support our students' selfdirected studies. As with mapping, perhaps it is not the "final product," the accomplishment of some imposed goal, but the continued process by which students explore and solve problems that is most important. We refer to Dewey's quote at the top of this paper, in which experience is expressed not as a "directed" activity, but as an ongoing phenomenon. Our final question ties all of these issues together: Where do we go with our findings? How do we make the most of the hours spent planning, designing, discussing, executing, mapping, and critiquing? The maps themselves tell a bigger story than lines or dots on a page might infer. They are the product of collective cognition - the product of many eyes, many hands, many brains. How do we use them to enhance our understanding of urban landscapes? Can this process guide students towards the act of creation, inspiring strategic proposals in the realms of ecological restoration, environmental management, neighborhood improvement, historic preservation, urban design, and other spatial and ecological realms? How do we use them to understand the landscape of learning?

\section{References}

Ackerman, A. and Garver, B.L. (2015) Social media as a visualization tool: Mapping the urban environment. Council of Education in Landscape Architecture, March, 2015. Manhattan, Kansas, USA. 
International Journal on Urban Environments

Bannon, L. and Bødker, S. (1997) Constructing common information spaces. Proceedings of the Fifth European Conference on Computer Supported Cooperative Work pp. 81-96. Kluwer Academic Publishers, Netherlands.

Benkler, Y. (2015) Peer Production and Cooperation. In: Bauer, J. M. and Latzer, M. (eds.). Handbook on the Economics of the Internet. Cheltenham, UK.: Edward Elgar Publishing.

Bloom, B. S., Engelhart, M.D., Furst, E.J., Hill, W.H. and Krathwohl, D.R. (1956) Taxonomy of Educational objectives: The Classification of Educational Goals. Handbook I: Cognitive domain. New York: David McKay Company.

Contin, A., Paolini, P. and Salerno, R. (eds.) (2014) Innovative Technologies in Urban Mapping: Built Space and Mental Space. New York: Springer.

Corner, J. (1999) The agency of mapping: Speculation, critique, and invention In: Cosgrove, D., (ed.) Mappings. London: Reaktion Books.

Das, R. (2011) Converging perspectives in audience studies and digital literacies: Youthful interpretations of an online genre. European Journal of Communication, Vol. 26 pp. 343-360.

Fok, W.W. (2015) Delineating crowd sourced ownership in the digital age for the built environment, pp. 43-52 Emerging Experience in Past, Present and Future of Digital Architecture, Proceedings of the 20th International Conference of the Association for Computer-Aided Architectural Design Research in Asia (CAADRIA 2015) / Daegu, Republic of South Korea, 20-22 May 2015.

Knoblauch, H., Baer, A., Laurier, E., Petschke, S., and Schnettler, B. (2008) Visual analysis. New Developments in the interpretative analysis of video and photography. Forum Qualitative Sozialforschung / Forum: Qualitative Social Research, Vol. 9(3), Art. 14.

Kurgan, L. (2013) Close up at a Distance: Mapping, Technology, and Politics. Brooklyn, NY: Zone Books.

Hammer, S. (2014) A phenomenological approach to engage students in learning urban ecology. Proceedings of the Second Annual Urban Design Conference, Reinventing Cities and Places, International Conference on Cities, People, and Places, -- ICCPP 2014, pp. 77-85. R. Dayaratne and J. Wijesundara, eds. Department of Architecture, University of Moratuwa, Sri Lanka.

Hammer, S. (2015) Abstract Reasoning in the Azores: Contributing and Contemplating at the Second International Interdisciplinary Conference. Impact 4: (unpaginated).

Marwick, A. \& D. Boyd. (2010) I tweet honestly, I tweet passionately: Twitter users, context collapse, and the imagined audience. New Media and Society 13: 114-133.

Ntmann, N., \& Hambourg, A. (2004) Mapping a City. Ostfildern: Hatje Cantz, O'Rourke, K. (2013) Walking and Mapping: Artists as Cartographers. Cambridge, MA, USA: MIT Press,

Ratto, M. \& Ree, R. (2013) Materializing 3D printing and social change. First Monday, Vol. 17: 7.

Somerson, R. \& Hernando, M. 2012. The Art of Critical Making: Rhode Island School of Design on Creative Practice. New York: Wiley. 